Check for updates

Cite this: RSC Adv., 2017, 7, 39160

Received 3rd June 2017

Accepted 1st August 2017

DOI: $10.1039 / c 7 r a 06219 b$

rsc.li/rsc-advances

\section{A highly carbon-resistant olivine thermally fused with metallic nickel catalyst for steam reforming of biomass tar model compound}

\author{
Junguang Meng, (D) abcd Xiaobo Wang, ${ }^{\text {abc }}$ Zengli Zhao, ${ }^{\text {abc }}$ Xianshuang Wu, ${ }^{\text {abcd }}$ \\ Anqing Zheng, ${ }^{\text {abc }}$ Guoqiang Wei, abce Zhen Huang ${ }^{\text {abc }}$ and Haibin Liabc
}

\begin{abstract}
Olivine has been shown to have a good catalytic effect on biomass tar, however, carbon deposition is still one of the adverse conditions that affect its activity. A highly carbon-resistant olivine-supported metallic nickel catalyst, which was synthesized using thermal fusion (TF), was tested in a fixed bed reactor for tar removal. Toluene was selected as a tar destruction model molecule. The current work evaluated three catalysts, namely, raw olivine, TF-olivine (olivine calcined at $1400{ }^{\circ} \mathrm{C}$ in air) and TF-Ni/olivine (TF-olivine loaded with $5 \%$ wt $\mathrm{Ni}$ calcined at $1400{ }^{\circ} \mathrm{C}$ in $\mathrm{Ar}$ ), for toluene steam reforming and investigated the effects of reaction temperature, steam to carbon molar ratio (S/C) and weight hourly space velocity (WHSV) on toluene conversion, carbon deposition and gas composition. Catalytic activity and resistance against carbon deposition were discussed based on physiochemical properties of the catalyst, including BET surface area, X-ray diffraction (XRD), X-ray photoelectron spectroscopy (XPS), scanning electron microscopy (SEM), temperature programmed reduction (TPR) and Laser Raman spectroscopy (LRS). The TF-Ni/olivine catalyst showed the best catalytic performance in terms of both toluene conversion and carbon deposition. A very low carbon deposition (less than $1 \%$ ) was obtained when the S/C ratio was 0.88 and 1.02. Relative amounts of reducible $\mathrm{Ni}, \mathrm{Fe}$ and $\mathrm{Mg}$ on the surface played a significant role in the catalytic behavior. Thermal fusion at a high temperature made the interaction between active metal and olivine structure stronger. The toluene conversion increased from $73.7 \%$ to $99.6 \%$ with the reaction temperature ranged from $750{ }^{\circ} \mathrm{C}$ to $950{ }^{\circ} \mathrm{C}$, however it decreased form $92.4 \%$ to $82.6 \%$ when the WHSV increased from $0.77 \mathrm{~h}^{-1}$ to $1.35 \mathrm{~h}^{-1}$, similarly it decreased slightly (96.9\% to $86.2 \%$ ) with the S/C ratio ranging from 0.29 to 1.02 . When comparing the characteristics between fresh and spent TF-Ni/olivine, the main structure and surface topography remained unchanged.
\end{abstract}

\section{Introduction}

Biomass gasification is a necessary component step of biomassbased renewable energy systems. By way of biomass gasification, biomass can be converted to fuel and chemicals that can be utilized in combined power production or combined heat. ${ }^{\mathbf{1 , 2}}$ However, the tar in the product gas has become one of the biggest problems in the industrialization of biomass-derived fuel gases. ${ }^{3}$ Currently, an economic process for tar elimination has not been found. A promising catalytic conversion method is

${ }^{a}$ Guangzhou Institute of Energy Conversion, Chinese Academy of Sciences (CAS), Guangzhou 510640, China. E-mail: wangxb@ms.giec.ac.cn

${ }^{b}$ CAS Key Laboratory of Renewable Energy, China

${ }^{c}$ Guangdong Provincial Key Laboratory of New and Renewable Energy Research and Development, China

${ }^{d}$ University of Chinese Academy of Sciences, Beijing 100049, China

${ }^{e}$ State Key Laboratory Breeding Base of Coal Science and Technology Co-founded by Shanxi Province, The Ministry of Science and Technology, Taiyuan University of Technology, China considered as an attractive approach for tar cracking because it has demonstrated improved biomass materials conversion and thermal efficiency. ${ }^{4-6}$

Ni catalysts have been investigated extensively for tar catalytic cracking due to their high tar destruction ability ${ }^{7-9}$ but they are limited due to the toxicity and rapid deactivation due to sintering and carbon deposition. ${ }^{\mathbf{1 0 , 1 1}}$

Catalysts based upon natural ore, such as olivine, dolomite, limestone and magnetite, are exciting candidate materials for tar removal due to their low cost and durable activity. Olivine, which is a silicate material mainly containing $\left(\mathrm{Mg}_{x} \mathrm{Fe}_{1-x}\right)_{2} \mathrm{SiO}_{4}$ and small quantities of $\mathrm{MgSiO}_{3}$ and $\mathrm{FeSiO}_{3}$ species, has been investigated in many forms. ${ }^{12,13}$ The literature suggests that olivine catalysts are considered to exhibit comparable activity as dolomites for tar cracking and reforming reactions due to the Fe or other active sites on their surfaces. ${ }^{14}$ In addition, olivine is attractive due to the advantage of high attrition resistance compared with other nature ore catalysts to satisfy the requirements of the FICFB (Fast Internally Circulating Fluidized Bed) or DFB (Dual Fluidized Bed). ${ }^{15-18}$ 
By combining their merits, a Ni/olivine catalyst has been investigated, characterized, developed and used as an in situ catalyst to remove $\operatorname{tar}^{19-21}$ In the current studies, Ni/olivine catalysts are mainly synthesized by incipient wetness impregnation (IWI). The results showed that they have better activity compared to olivine alone during steam reforming of tar. ${ }^{22,23}$ Another hopeful loading method for FICFB and DFB has been studied, i.e., thermal fusion (TF), to integrate $\mathrm{Ni}$ onto olivine catalysts at more than $1400{ }^{\circ} \mathrm{C}$. More stable activities, lower carbon deposition rates and better abrasion resistance for tarsteam reforming were obtained compared to the olivine synthesized by IWI. ${ }^{24,25}$ The advanced property was ascribed to the Ni-Fe alloy which can prevent coking by changing the electronic structure of the metallic phase in the olivine lattice; the advanced property was also ascribed to the generation of a $(\mathrm{Mg}, \mathrm{Ni}) \mathrm{O}$ or $\mathrm{MgO}$ solid solution which can decrease the carbon deposition through its basic nature. ${ }^{26,27}$

In the present work, to understand better the catalyst precursors and reaction parameters influencing on tar steam reforming activity, toluene was selected as a simplified tar model molecule because it presents a stable aromatic structure during tar generation. We synthesized olivine and olivine supported nickel using TF to demonstrate their efficiencies in the steam reforming of toluene, as well as their abilities for carbon resistance. The efficacies of the catalysts were tested when different precursors (raw olivine, TF-olivine and TF-Ni/olivine) and different operating parameters (reaction temperature, S/C ratio and WHSV) were used. Physiochemical properties, including both surface (BET surface area and XPS) and structural analyses (XRD, TPR, and Raman spectroscopy), were investigated for both fresh and spent olivine catalysts. The relevance between the catalytic activities (toluene conversion and carbon deposition) and the characteristics of the catalysts was determined.

\section{Experimental}

\subsection{Catalyst preparation}

Olivine catalysts were obtained from Yichang Fuquan Olivine Company. The samples were screened in the $380-830 \mu \mathrm{m}$ range (20-40 mesh) by mechanical treatments (marked as raw olivine) and then calcined at $1400{ }^{\circ} \mathrm{C}$ for $4 \mathrm{~h}$ in air (marked as TFolivine). Metallic $\mathrm{Ni}$ ( $5 \% \mathrm{Ni}$ by mass) as the Ni precursor was incorporated onto TF-olivine supports directly and then stir evenly, the mixture was calcined at $1400^{\circ} \mathrm{C}$ for $4 \mathrm{~h}$ in $\mathrm{Ar}$ (marked as TF-Ni/olivine). Following this treatment, TF-olivine and TF$\mathrm{Ni}$ /olivine were physically ground to the same size as raw olivine $(380-830 \mu \mathrm{m})$ before catalytic characterization studies and reaction tests of toluene catalytic cracking.

\subsection{Reaction testing}

Steam reforming reactions were investigated using toluene as a model tar compound. The scheme of the experimental apparatus is shown in Fig. 1. Toluene and water were injected into the reactor with a high purity nitrogen stream. The flow rates of toluene and water were controlled by calibrated peristaltic pumps, and $\mathrm{N}_{2}$ was controlled by a mass flow controller. The experiments were conducted in a fixed bed with a quartz reactor ( $25 \mathrm{~mm}$ i.d.) placed in the furnace. Olivine catalysts were placed on a porous frit in the middle of the quartz reactor. The reaction temperature was monitored by a thermocouple placed near the catalyst bed and was controlled with a computer controller. The rear section of the reactor was a scrubbing bottle with isopropanol for absorbing unreacted toluene. A bottle filled with desiccant was connected to the tail of the absorbent bottle to dry the gas. The gas generated in the reaction was collected in a value bag for analysis with GC-7890A (GS-GASPRO (FID) and 6 $\mathrm{ft} \mathrm{Q}+8 \mathrm{ft} 5 \mathrm{~A}$ with $6 \mathrm{ft} 5 \mathrm{~A}$ (TCD)). The total volume of gas and volume of gas components were calculated by $\mathrm{N}_{2}$ balanced before and after the reaction. The unreacted toluene in isopropanol was analyzed with GC (FID, Agilent HP-5 capillary column).

After the toluene steam reforming reactions, dry air was bubbled into the furnace at $850{ }^{\circ} \mathrm{C}$ to burn the carbon attached to the surface of the catalyst. The content of carbon deposited on the catalyst was calculated by measuring the contents of $\mathrm{CO}$ and $\mathrm{CO}_{2}$.

The gas components, toluene conversion and carbon deposition rate were calculated using the following definitions:

Volume percent of gas components, denoted as $\varphi_{\mathrm{i}}$ (eqn (1)), is the ratio of the volume of gas components $\left(V_{\mathrm{i}}\right)$ to the volume of total gas $(\mathrm{V})$ generated in the reactions.

$$
\varphi_{\mathrm{i}}(\%)=\frac{V_{\mathrm{i}}}{V} \times 100 \%, \quad \mathrm{i}=\mathrm{CO}, \mathrm{CO}_{2}, \mathrm{H}_{2}, \mathrm{CH}_{4}
$$

Toluene conversion, denoted as $C_{\mathrm{T}}$ (eqn (2)), is the ratio of the difference between injected toluene $\left(m_{\mathrm{i}}\right)$ and unreacted toluene $\left(m_{\mathrm{o}}\right)$ to the injected toluene $\left(m_{\mathrm{i}}\right)$.

$$
C_{\mathrm{T}}(\%)=\frac{m_{\mathrm{i}}-m_{\mathrm{o}}}{m_{\mathrm{i}}} \times 100 \%
$$

Carbon deposition rate, denoted as $Y_{\mathrm{c}}$ (eqn (3)), is the ratio of the mass of carbon deposition $\left(m_{\mathrm{c}}\right)$ to the mass of reacted toluene $\left(m_{\mathrm{i}}-m_{\mathrm{o}}\right)$.

$$
Y_{\mathrm{c}}(\%)=\frac{m_{\mathrm{c}}}{m_{\mathrm{i}}-m_{\mathrm{o}}} \times 100 \%
$$

\subsection{Catalyst characterization}

The olivine catalysts were characterized using XRD (X'Pert-PRO MPD) with $\mathrm{Cu} K \alpha$ radiation $(\lambda=1.54060 \AA)$ at $40 \mathrm{kV}$ and $40 \mathrm{~mA}$. The diffraction patterns were registered from $2 \theta=5-80^{\circ}$ at a scanning rate of $2^{\circ} \mathrm{min}^{-1}$. The surface morphologies of the olivine catalysts were obtained by scanning electron microscopy (SEM) using a Hitachi S4800 instrument. Transmission electron microscopy (TEM) were measured on a Jeol TEM-100CX instrument at $200 \mathrm{kV}$ accelerating voltage. The samples were crushed to fine powders, then dispersed in ethanol by supersonic waves and put on $\mathrm{Cu}$ grid with a holey carbon film under atmosphere. Laser Raman spectroscopy (LRS) of fresh and spent reaction samples were collected on a Horiba Labor HR800 


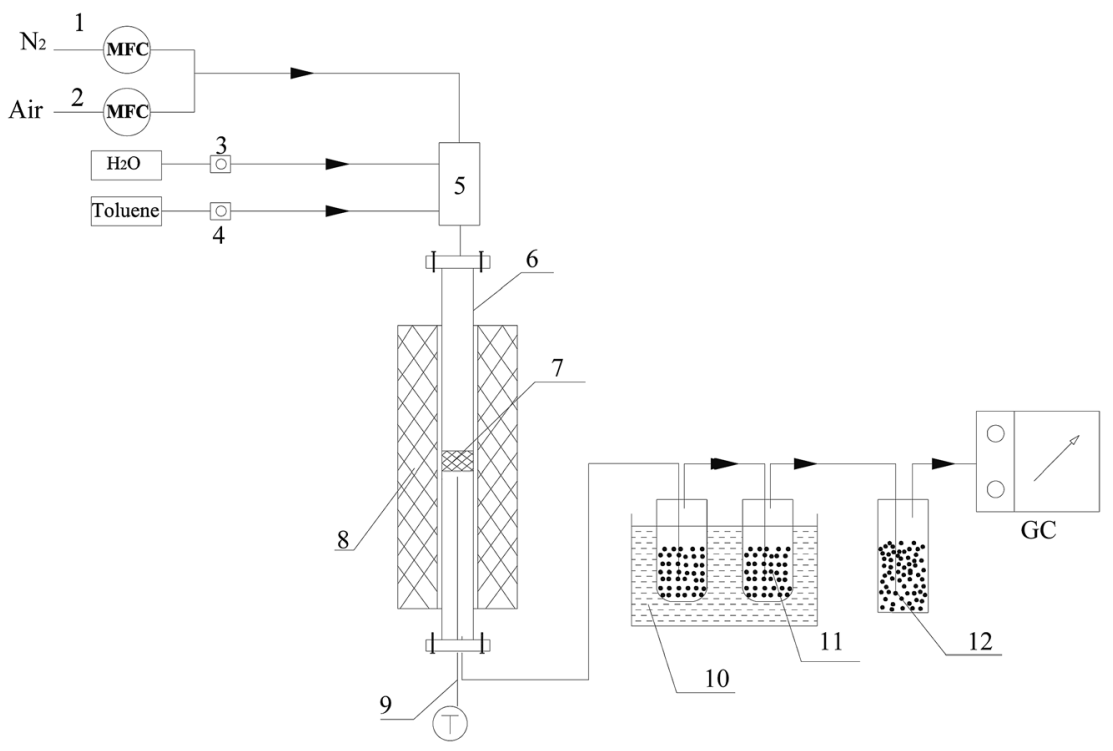

Fig. 1 Experimental scheme of $\mathrm{C}_{7} \mathrm{H}_{8} / \mathrm{H}_{2} \mathrm{O}$ reforming. (1, 2) Mass flowmeter, $(3,4)$ peristaltic pump, (5) commingler (6) quartz reactor, (7) catalyst, (8) furnace, (9) thermocouple, (10) condenser, (11) isopropanol, (12) dryer.

system using an excitation line of $633 \mathrm{~nm}$. The specific surface areas and average pore diameter were measured by the Brunauer-Emmett-Teller (BET) method at liquid nitrogen temperature based on the adsorption isotherm. To calculate the amount of reducible nickel and iron on the surface of olivine catalyst, the olivine's reducibility was measured by hydrogen temperature programmed reduction $\left(\mathrm{H}_{2}\right.$-TPR), which was followed by $5 \%$ vol. $\mathrm{H}_{2}$ balanced with helium from room temperature to $950{ }^{\circ} \mathrm{C}$ at a rate of $10^{\circ} \mathrm{C} \mathrm{min}{ }^{-1}$, and then isothermally kept at $950{ }^{\circ} \mathrm{C}$ for $30 \mathrm{~min}$. To investigate the near-surface composition of the catalysts, X-ray photoelectron spectroscopy (XPS) was conducted using a Kratos Ultra Spectrometer in ESCALAB 250 Xi equipment, Thermo Fisher Scientific Inc. An Al $\mathrm{K} \alpha \mathrm{X}$-ray source $(10 \mathrm{~mA}, 20 \mathrm{kV})$ was used under the pass energy conditions of $20 \mathrm{eV}$ and $100 \mathrm{eV}$ for the survey spectra and the single element spectra $(\mathrm{Fe}, \mathrm{Ni})$, respectively.

\section{Results and discussion}

\subsection{Screening of olivine catalysts}

Three olivine catalysts (raw olivine, TF-olivine and TF-Ni/ olivine) were investigated in toluene steam reforming under the following operating parameters: reaction temperature of $850{ }^{\circ} \mathrm{C}, \mathrm{S} / \mathrm{C}$ ratio of 0.88 and WHSV of 0.9 .

This experiment mainly examined the toluene conversion rate, carbon deposition rate, gas components during the reaction and the characterization of fresh olivine catalysts.

3.1.1 Characterization of olivine catalysts. The surface topography of raw olivine is rough, as shown by Fig. 2(a). After calcination at $1400{ }^{\circ} \mathrm{C}$ (Fig. 2(b)), the surface topography becomes smooth and compact and it does not change drastically when loaded with Ni (Fig. 2(c)). The surface areas of these three olivine catalysts show a similar tendency. The surface area of the raw olivine was $16.805 \mathrm{~m}^{2} \mathrm{~g}^{-1}$, while that of TF-olivine and TF-Ni/olivine were only approximately $1 \mathrm{~m}^{2} \mathrm{~g}^{-1}$ as shown in Table 1, which indicates that the olivine itself is not a polyporous material. The SEM-EDS results of TF-Ni/olivine show that the additional $\mathrm{Ni}$ element is evenly distributed on the surface as shown in Fig. 2(d) and (e).

Fig. 3 shows the XRD diagrams of raw olivine, TF-olivine and TF-Ni/olivine. As shown in the XRD patterns, raw olivine is mainly made of serpentine phase $\left(\mathrm{Mg}_{3} \mathrm{Si}_{2} \mathrm{O}_{5}(\mathrm{OH})_{4}\right)$. After calcination, the serpentine phase disappears and new phases $\mathrm{Mg}_{2} \mathrm{SiO}_{4}$ and $\mathrm{MgSiO}_{3}$ appear. This change can be described by the following reactions at high temperature: ${ }^{28}$

$$
\begin{gathered}
(\mathrm{Mg}, \mathrm{Fe})_{2} \mathrm{SiO}_{4}+\mathrm{O}_{2} \rightarrow \\
\chi \mathrm{Mg}_{2} \mathrm{SiO}_{4}+(2 \chi-1) \mathrm{Fe}_{2} \mathrm{O}_{3}+(1-\chi) \mathrm{SiO}_{2}+2(1-\chi) \mathrm{MgFe}_{2} \mathrm{O}_{4} \\
\mathrm{Mg}_{3} \mathrm{Si}_{2} \mathrm{O}_{5}(\mathrm{OH})_{4} \rightarrow \mathrm{Mg}_{2} \mathrm{SiO}_{4}+\mathrm{SiO}_{2}+\mathrm{H}_{2} \mathrm{O} \\
\mathrm{Mg}_{2} \mathrm{SiO}_{4}+\mathrm{SiO}_{2} \rightarrow 2 \mathrm{MgSiO}_{3}
\end{gathered}
$$

$\mathrm{Fe}_{2} \mathrm{O}_{3}$ phase is discovered in TF-olivine, and the diffraction pattern of TF-Ni/olivine is similar to that of TF-olivine. In addition, metallic $\mathrm{Ni}$ and $\mathrm{Fe}-\mathrm{Ni}$ alloy are observed in the TF$\mathrm{Ni} /$ olivine structure after adding metallic Ni. The decrease in the intensities of the (112) and (131) lines of TF-Ni/olivine indicates that the olivine structure is rearranged. For example, the growth of the (310) line relative to the (130) and (112) lines suggests that the $\mathrm{Mg}$ concentration decreases in the olivine phase, while the peaks intensity of $(\mathrm{Ni}, \mathrm{Mg})_{2} \mathrm{SiO}_{4}$ increases in TF-Ni/olivine, which indicates some $\mathrm{Ni}$ in place of $\mathrm{Mg}$ in the olivine lattice. This phenomenon suggests that the exchange of $\mathrm{Ni}$ and $\mathrm{Mg}$ in the olivine phase could contribute to the formation of a strong interaction between metallic Ni and TF-Ni/olivine structure. ${ }^{27}$ 


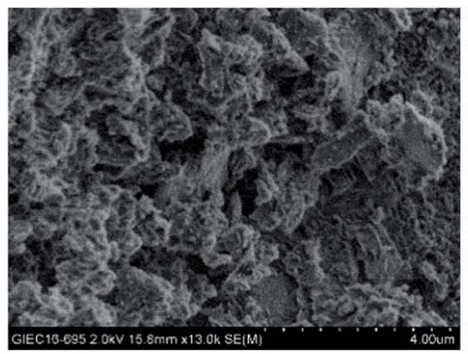

(a)

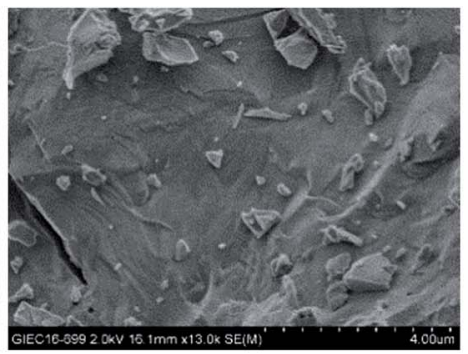

(b)

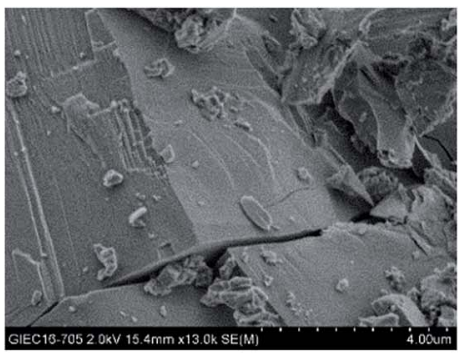

(c)

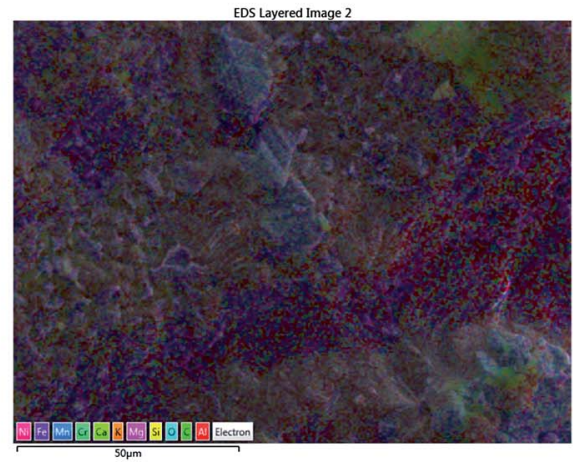

(d)

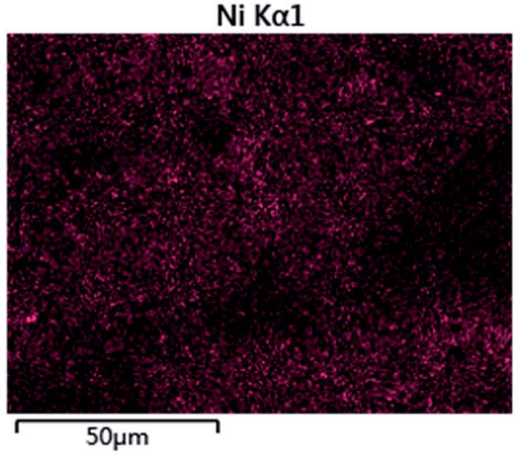

(e)

Fig. 2 SEM/EDS images of differently treated olivine catalysts. (a) SEM image of raw olivine (b) SEM image of TF-olivine (c) SEM image of TF-Ni/ olivine (d) EDS image of TF-Ni/olivine (e) Distribution of Ni on TF-Ni/olivine.

Laser Raman spectra are obtained to supplement the XRD analysis, as shown in Fig. 4. Olivine is a major species as recognized by some strong vibrations. Forsterite olivine has been discussed previously ${ }^{29-31}$ and is used to indicate the bands of the olivine structure in this study. The bands of raw olivine are obviously different from those of TF-olivine and TF-Ni/ olivine, which are similar to the XRD patterns. The primary phase of raw olivine is the serpentine phase, which was previously shown using Laser Raman spectroscopy. ${ }^{32,33}$ The bands at $230,355,385,477,621,680 \mathrm{~cm}^{-1}$ are caused by the serpentine phase. The band at $131 \mathrm{~cm}^{-1}$ may be due to the serpentine phase according to the literature. ${ }^{26}$ After calcination, the peak strength of the serpentine phase weakens but could still be detected. The bands near 823, 856, 883, 921 and $966 \mathrm{~cm}^{-1}$ are caused by $\mathrm{SiO}_{4}$ stretching in the olivine structure. The lower wavenumber band $\left(331 \mathrm{~cm}^{-1}\right)$ is due to $\mathrm{MgFe}_{2} \mathrm{O}_{4}$.

An advantage of Laser Raman spectra is that the compounds of the samples with similar structures $\left(\right.$ e.g., $\gamma-\mathrm{Fe}_{2} \mathrm{O}_{3}$ and $\left.\mathrm{Fe}_{3} \mathrm{O}_{4}\right)$ could

Table 1 Surface area and average pore diameter of differently treated olivine catalysts

\begin{tabular}{lcl}
\hline Sample & $\begin{array}{l}\text { Surface area } \\
A /\left(\mathrm{m}^{2} \mathrm{~g}^{-1}\right)\end{array}$ & $\begin{array}{l}\text { Average pore } \\
\text { diameter } d / \mathrm{nm}\end{array}$ \\
\hline Raw olivine & 16.81 & 4.31 \\
TF-olivine & 1.02 & 0.01 \\
TF-Ni/olivine & 1.21 & 0.08
\end{tabular}

be confirmed. The primary bands of $\mathrm{Fe}_{3} \mathrm{O}_{4}$ near 307, 532, $667 \mathrm{~cm}^{-1}$ are not detected. However, the primary bands of $\gamma-\mathrm{Fe}_{2} \mathrm{O}_{3}$ near 665 and $721 \mathrm{~cm}^{-1}$ are detected in TF-olivine. Additionally, the primary bands of $\alpha-\mathrm{Fe}_{2} \mathrm{O}_{3}$ near 223, 291, and $407 \mathrm{~cm}^{-1}$ (ref. 34 and 35) are also detected in TF-Ni/olivine. $\mathrm{MgSiO}_{3}$ (primary bands at 1011 and $1033 \mathrm{~cm}^{-1}$ ) is observed in TF-olivine and TF-Ni/olivine.

The surface compositions of the three olivine catalysts are examined by XPS. The region scans of $\mathrm{Fe}$ and $\mathrm{Ni}$ are shown in

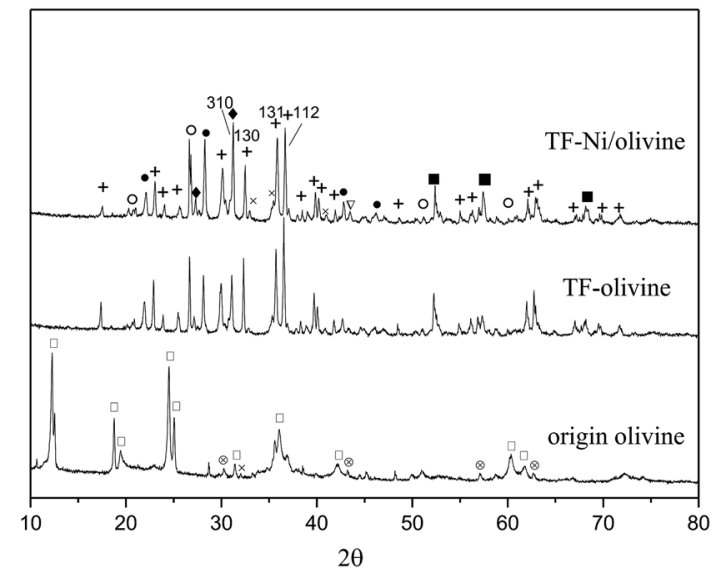

Fig. 3 XRD patterns of differently treated olivine catalysts. $+: \mathrm{Mg}_{2} \mathrm{SiO}_{4}$; $\leftrightarrow: \mathrm{MgSiO}_{3} ; \mathrm{O}:(\mathrm{Fe}, \mathrm{Ni}) ; \times: \mathrm{Fe}_{2} \mathrm{O}_{3} ; \nabla: \mathrm{Ni} ; \square: \mathrm{Mg}_{3} \mathrm{Si}_{2} \mathrm{O}_{5}(\mathrm{OH})_{4} ; \otimes:$ $\mathrm{MgFe}_{2} \mathrm{O}_{4} ; \mathbf{\square}:(\mathrm{Ni}, \mathrm{Mg})_{2} \mathrm{SiO}_{4}$. 


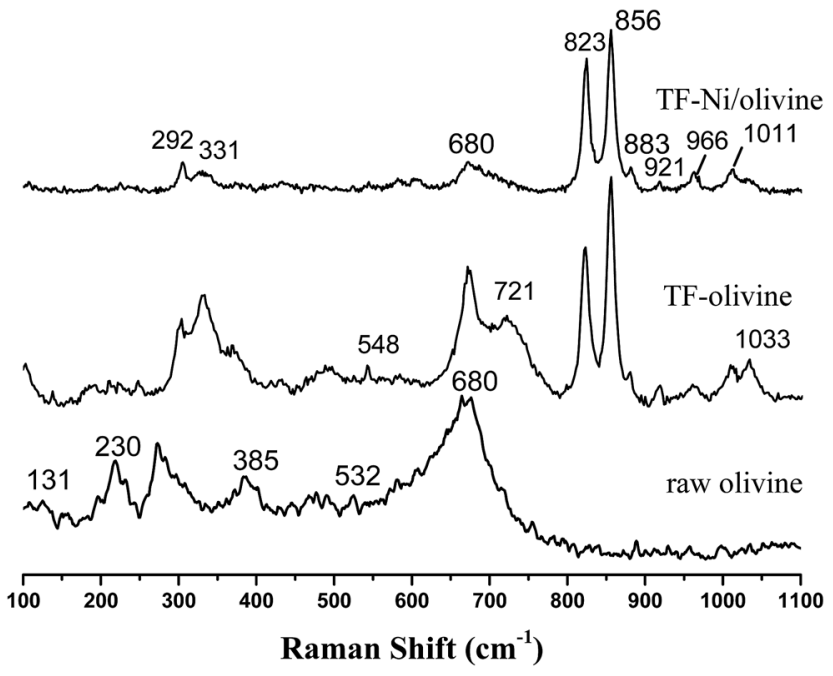

Fig. 4 Laser Raman spectra of differently treated olivine catalysts.

Fig. 5. These elements are important due to their significance in the active sites. For the olivine catalysts, the $\mathrm{Fe}$ peaks near $711.7 \mathrm{eV}\left(2 \mathrm{p}_{3 / 2}\right)$ and $724 \mathrm{eV}\left(2 \mathrm{p}_{1 / 2}\right)$ are $\mathrm{Fe}_{2} \mathrm{O}_{3}$ on the surface of olivine. The $\mathrm{Fe} 2 \mathrm{p}$ peaks of $\mathrm{TF}$-olivine and $\mathrm{TF}-\mathrm{Ni} /$ olivine are stronger than the peaks of raw olivine, which corresponds to the results of XRD and Laser Raman spectra. ${ }^{36}$ After Ni incorporation, no obvious transformation in the binding energy is observed and no metallic $\mathrm{Fe}$ (near $707 \mathrm{eV}, 2 \mathrm{p}_{3 / 2}$ ) is found. Metallic ( $2 \mathrm{p}_{3 / 2}$ near $854.7 \mathrm{eV}, 2 \mathrm{p}_{1 / 2}$ near $\left.872.0 \mathrm{eV}\right)$ and oxidized $\left(2 \mathrm{p}_{3 / 2}\right.$ near $856.2 \mathrm{eV}, 2 \mathrm{p}_{1 / 2}$ near $\left.873.3 \mathrm{eV}\right) \mathrm{Ni}$ are observed on the surface of TF-Ni/olivine. ${ }^{27}$ While the peaks near 856.2 and $878.0 \mathrm{eV}$ are the satellite band of NiO. ${ }^{37,38}$ Since metallic $\mathrm{Ni}$ is a precursor, the appearance of oxidized Ni species indicates an intense interaction between $\mathrm{Ni}$ and the olivine structure because the calcination was conducted in an Ar atmosphere. The peaks of metallic and oxidized Ni are not found in the other two olivine catalysts. This phenomenon shows that the raw olivine contains a small amount of $\mathrm{Ni}$.

To investigate the reducing property of olivine catalysts, $\mathrm{H}_{2}$ TPR tests were carried out on the three olivine catalysts, as

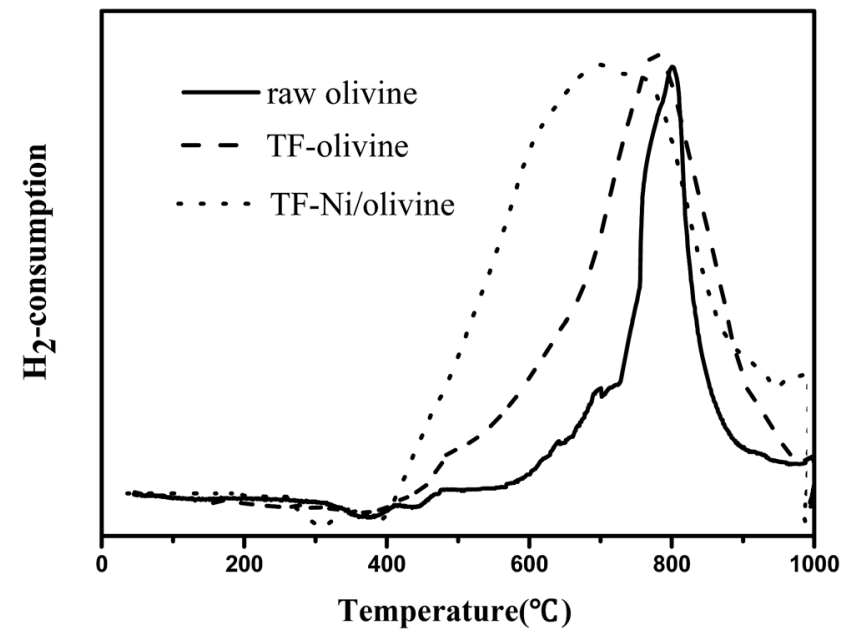

Fig. $6 \mathrm{H}_{2}$-TPR of differently treated olivine catalysts.

shown in Fig. 6. The results of hydrogen chemisorption showed that the amount of $\mathrm{H}_{2}$ adsorption over raw olivine, TF-olivine and TF-Ni/olivine were $96.47,154.43,347.25 \mu \mathrm{mol} \mathrm{g}_{\text {cat }}{ }^{-1}$ respectively. The reduction profile of raw olivine has only one reduction zone and its reductive peak is at $800{ }^{\circ} \mathrm{C}$. This narrow peak is attributed to the reduction of $\mathrm{Fe}_{2} \mathrm{SiO}_{4}$ and $\mathrm{MgFe}_{2} \mathrm{O}_{4}$ associated with the olivine structure. The width of the reduction peak increases after calcination at $1400{ }^{\circ} \mathrm{C}$ both with and without Ni. And the temperature of the main reduction peaks of them both shift to lower temperature. During the calcination process, the ferrous ions in the olivine phase $(\mathrm{Mg}, \mathrm{Fe})_{2} \mathrm{SiO}_{4}$ are partially oxidized to ferric ions. In order to keep the charge balance, ferric ions dissociate to the surface to form $\mathrm{Fe}_{2} \mathrm{O}_{3}$, causing the iron material in the olivine structure to be more easily reduced. A weak reductive peak appears at $500{ }^{\circ} \mathrm{C}$ for TF-olivine. This peak may be caused by free iron oxides $\left(\mathrm{Fe}_{2} \mathrm{O}_{3}\right)$ on the surface of olivine as shown in the XRD spectrograms. After loading Ni, the width of the reductive peak further increases, which indicates that there are more reducible oxide species than olivine without Ni. What's more, no significant reduction peak of $\mathrm{NiO}$ is found in the spectra. These results also suggest the strengthening of the
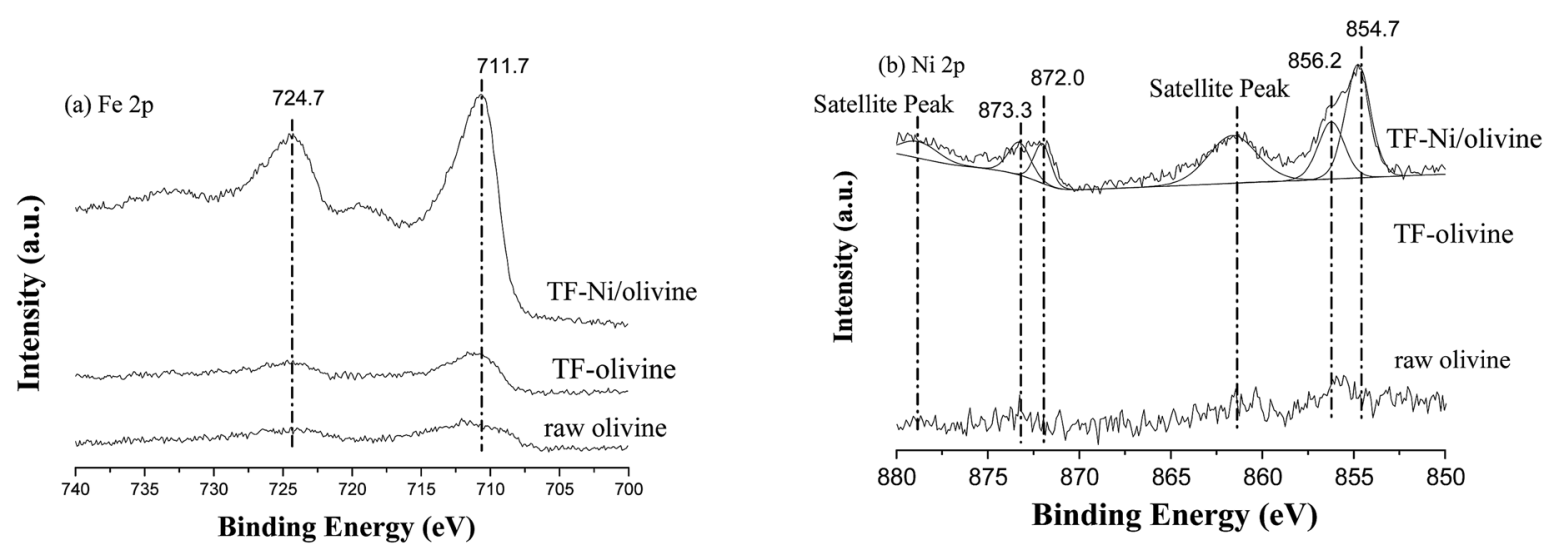

Fig. 5 X-ray photoelectron spectra of differently treated olivine catalysts: effects of (a) Fe $2 p$ and (b) Ni 2p. 


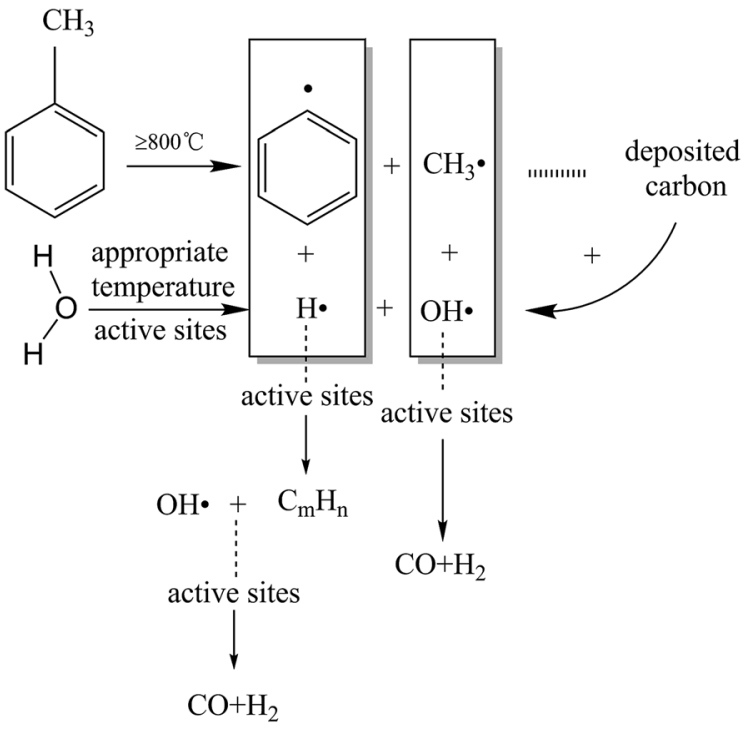

Fig. 7 Schematic diagram of the reaction paths of toluene steam reforming.

interaction between $\mathrm{Ni}$ and olivine so that only one reducible peak appears instead of respective reducible peaks.

3.1.2 Catalytic effects of the olivine catalysts. Toluene steam reforming studies were carried out using the three olivine catalysts at $850{ }^{\circ} \mathrm{C}$ with an S/C ratio of 0.88 and a WHSV of $0.9 \mathrm{~h}^{-1}$. The results (Fig. 8) show that the toluene conversion of raw olivine is only approximately $60 \%$; as shown in the catalyst characterization (Section 3.1.1), it has less active components and reducible species on the surface. ${ }^{12,14} \mathrm{TF}-$ olivine and TF-Ni/ olivine perform better in the toluene steam reforming compared with raw olivine, and the toluene conversions reach approximately $90 \%$. However, the high carbon deposition of TFolivine $(25.78 \%)$ seems to be a logical consequence compared with TF-Ni/olivine $(0.79 \%)$, and a similar literature also showed that monometallic $\mathrm{Ni}$ particles tend to give non-reactive carbonaceous species more preferably for tar steam reforming than $\mathrm{Fe}-\mathrm{Ni}$ alloy particles in the hydrotalcite-like catalyst. ${ }^{39}$ Monometallic Ni has been exhibited much higher reforming activity of hydrocarbons than monometallic Fe catalysts because of its high activation ability of $\mathrm{C}-\mathrm{H}$ and $\mathrm{C}-\mathrm{C}$ bond. However, $\mathrm{Fe}$ has a high oxygen affinity than $\mathrm{Ni}$, during the steam reforming, the oxygen atoms on Fe species can be supplied to the Ni species to promote the reaction between carbonaceous species on $\mathrm{Ni}$ and oxygen species. ${ }^{40-42}$ When the temperature is higher than $800{ }^{\circ} \mathrm{C}$, the toluene tends to crack to methyl and phenyl groups on the $\mathrm{Ni}$ species. As shown in Fig. 7, at a suitable temperature, the added water migrates to the oxide support and active sites on the surface of the catalyst. The dissociated hydrogen can hydrogenate the aromatic rings to constitute a saturated group, which can be destroyed easily into hydrocarbon fragments with the action of $\mathrm{Ni}$ species and then transformed into $\mathrm{CO}+\mathrm{H}_{2}$ combined with hydroxide radicals with the help of Fe species. The hydroxide radicals may also migrate to the active sites (mainly on the Fe species) and incorporate with the methyl groups and deposited carbon to form $\mathrm{CO}+\mathrm{H}_{2} \cdot{ }^{22,40,43}$ Combining the characterization analyses of raw olivine and TF-olivine catalysts, the active sites of TF-Ni/olivine not only contain $\mathrm{Fe}_{2} \mathrm{O}_{3}$ but also include $\mathrm{Fe}-\mathrm{Ni}$ alloy and $(\mathrm{Ni}, \mathrm{Mg})_{2} \mathrm{SiO}_{4}$ when metallic $\mathrm{Ni}$ is added. Generally, Fe atoms tend to be loaded on the surface of the alloy particles, which is more conducive to adsorb the oxygen atoms, to promote the reaction of steam and carbon deposited on the $\mathrm{Ni}$ active sites. Meanwhile, the Fe-Ni alloy catalysts with $\mathrm{MgO}$ could decrease the $\mathrm{Ni}$ reducibility and promote the dispersion of Ni metal particle..$^{44,45}$ These factors all contribute to the improvement of catalytic activity and resistance to carbon deposition on olivine catalysts.

The $\mathrm{CO}$ contents for TF-olivine and TF-Ni/olivine are higher than those of raw olivine and the $\mathrm{CH}_{4}$ content is lower than that of raw olivine. This is because $\mathrm{Fe}_{2} \mathrm{O}_{3}$ and metallic and oxidized $\mathrm{Ni}$ can promote $\mathrm{CH}_{4}$ reforming. Otherwise, the gas production rates of TF-olivine and TF-Ni/olivine are higher than that of raw olivine, which can be explained by the fact that along with the increase of active substances, an increasing number of toluene is converted into small-molecule gases.

\subsection{Influence of reaction conditions on steam reforming using the TF-Ni/olivine catalyst}

The TF-Ni/olivine catalyst performs the best in toluene steam reforming among the three olivine catalysts in the
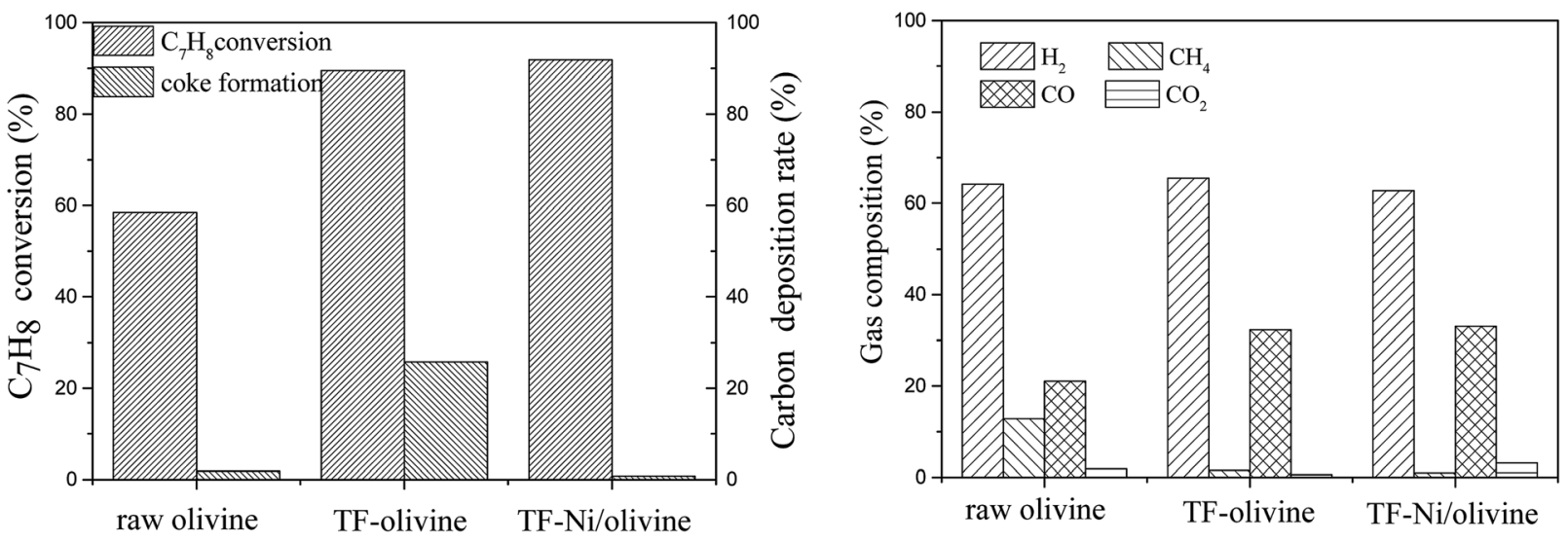

Fig. 8 Effects of three olivine catalysts on toluene $/ \mathrm{H}_{2} \mathrm{O}$ reforming (reaction temperature of $850{ }^{\circ} \mathrm{C}, \mathrm{S} / \mathrm{C}=0.88, \mathrm{WHSV}=0.9 \mathrm{~h}^{-1}$ ). 

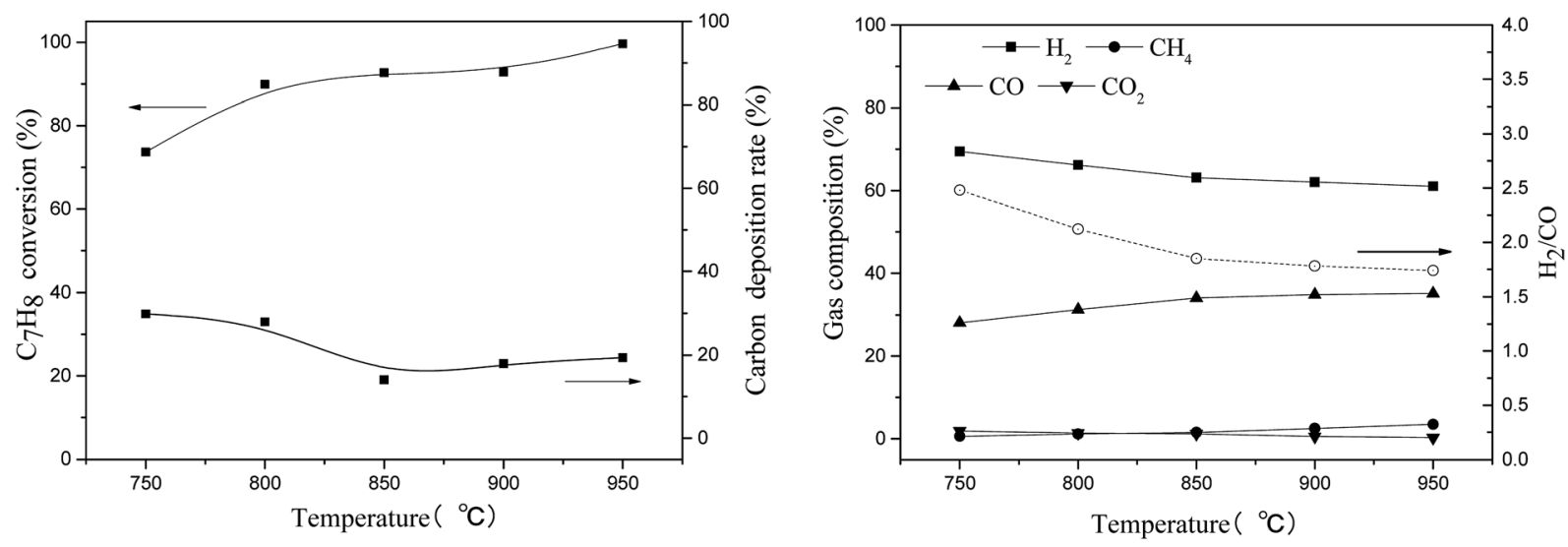

Fig. 9 Effect of reaction temperature on toluene steam reforming using TF-Ni/olivine $\left(\mathrm{S} / \mathrm{C}=0.73, \mathrm{WHSV}=0.9 \mathrm{~h}^{-1}\right.$ ).

abovementioned studies. Therefore, the TF-Ni/olivine catalyst is selected to investigate the effect of reaction conditions, namely, reaction temperature, WHSV and S/C ratio, on toluene steam reforming.

At high temperatures, toluene undergoes the following cracking reactions:

Direct cracking without oxidizing agent (eqn (7)):

$$
\mathrm{C}_{7} \mathrm{H}_{8} \rightarrow \mathrm{C}+\mathrm{CH}_{4}+\mathrm{C}_{2} \mathrm{H}_{4}+\mathrm{C}_{m} \mathrm{H}_{n} \cdots
$$

Reacting principally with water to produce carbon monoxide and hydrogen (eqn (8)):

$$
\mathrm{C}_{7} \mathrm{H}_{8}+7 \mathrm{H}_{2} \mathrm{O} \rightarrow 7 \mathrm{CO}+11 \mathrm{H}_{2}, \Delta H_{900}{ }^{\circ} \mathrm{C}=876 \mathrm{~kJ} \mathrm{~mol}^{-1}
$$

Or carbon dioxide and hydrogen (eqn (9)):

$\mathrm{C}_{7} \mathrm{H}_{8}+14 \mathrm{H}_{2} \mathrm{O} \rightarrow 7 \mathrm{CO}_{2}+18 \mathrm{H}_{2}, \Delta H_{900}{ }^{\circ} \mathrm{C}=647 \mathrm{~kJ} \mathrm{~mol}^{-1}$

3.2.1 Effect of reaction temperature. Tests of toluene steam reforming were investigated in the temperature range of 750$950{ }^{\circ} \mathrm{C}$ with an $\mathrm{S} / \mathrm{C}$ ratio of 0.73 and WHSV of $0.9 \mathrm{~h}^{-1}$. Toluene and water were introduced in the flow in stoichiometric conditions respectively. The performances of the catalyst are shown in Fig. 9.

Toluene conversion increases with the increase of reaction temperature from $750{ }^{\circ} \mathrm{C}$ to $950{ }^{\circ} \mathrm{C}$, suggesting that high temperature promotes a positive response in (eqn (8)). The carbon deposition rate decreases when the reaction temperature is lower than $850{ }^{\circ} \mathrm{C}$ but changes little in the temperature range of $850-950{ }^{\circ} \mathrm{C}$, which indicates that a higher temperature helps the carbon elimination reaction (eqn (10)). Because the amount of steam is not sufficient to allow the reaction to proceed exactly according to eqn (8), the carbon produced by the cracking of toluene will not be completely eliminated. The toluene conversion continues to increase when the reaction temperature becomes higher than $850{ }^{\circ} \mathrm{C}$ along with a corresponding increase in the carbon deposition. However, the steam is limited, and therefore, the carbon deposition rate increases slightly.

$$
\mathrm{C}+\mathrm{H}_{2} \mathrm{O} \leftrightarrow \mathrm{CO}+\mathrm{H}_{2}, \Delta H_{800}{ }^{\circ} \mathrm{C}=131 \mathrm{~kJ} \mathrm{~mol}^{-1}
$$

For the gas compositions, the content of $\mathrm{CO}$ gradually increases with the increase of temperature, partly because the
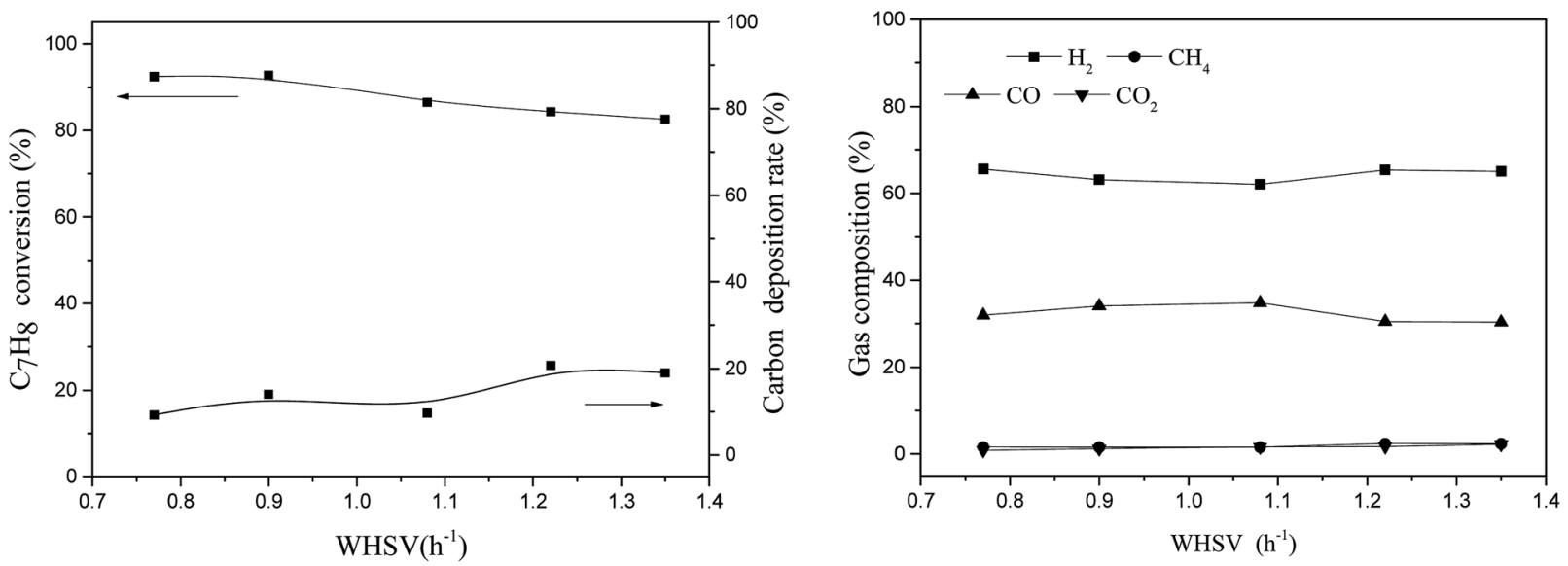

Fig. 10 Effect of WHSV on toluene steam reforming using TF-Ni/olivine (reaction temperature of $850{ }^{\circ} \mathrm{C}, \mathrm{S} / \mathrm{C}=0.73$ ). 

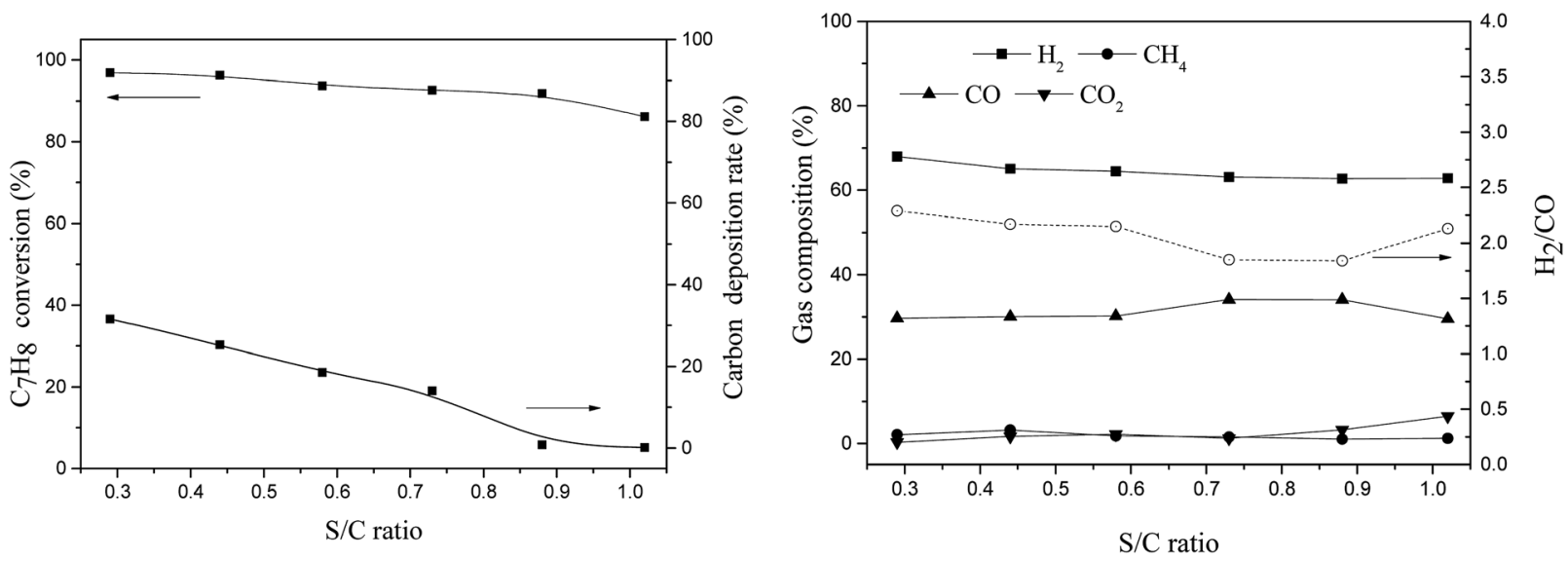

Fig. 11 Effect of the S/C ratio on toluene steam reforming using TF-Ni/olivine (reaction temperature of $850{ }^{\circ} \mathrm{C}, \mathrm{WHSV}=0.9 \mathrm{~h}^{-1}$ ).

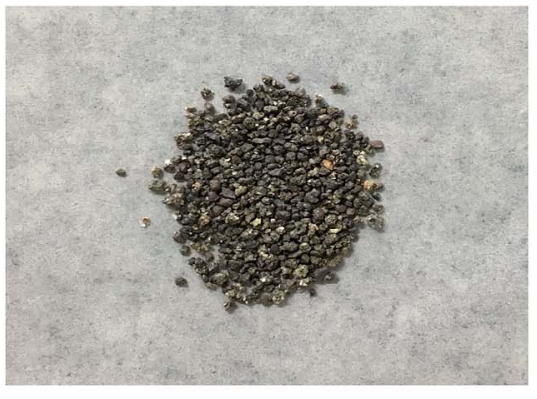

(a)

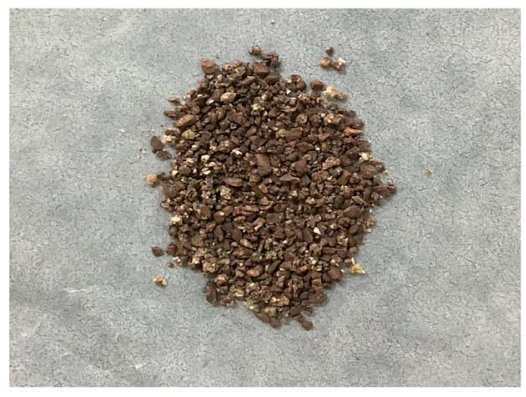

(b)

Fig. 12 Intuitive morphology of the TF-Ni/olivine catalysts: (a) fresh TF-Ni/olivine (b) spent TF-Ni/olivine.

increase in temperature contributes to a positive direction in eqn (10) and because the toluene conversion rate continues to rise, which can produce $\mathrm{CO}$. At the same time, the rate of $\mathrm{H}_{2} / \mathrm{CO}$ becomes closer to 1.57 as the temperature increases and steam is consumed completely.

3.2.2 Effect of weight hourly space velocity (WHSV). WHSV is the ratio of toluene feed weight per hour to the olivine catalyst, which indicates the catalytic ability in toluene steam reforming. The WHSV effects were studied at a temperature of
$850{ }^{\circ} \mathrm{C}$ and an $\mathrm{S} / \mathrm{C}$ ratio of 0.73 . At given flow rates of toluene and steam, the WHSV was controlled from 0.77 to 1.35 by changing the amount of the TF-Ni/olivine catalyst. The results are shown in Fig. 10. When the WHSVs are $0.77 \mathrm{~h}^{-1}$ and $0.9 \mathrm{~h}^{-1}$, the toluene conversions are almost equal but the carbon deposition of $0.9 \mathrm{~h}^{-1}$ is slightly higher than that of $0.77 \mathrm{~h}^{-1}$. Then, the toluene conversion decreases and carbon deposition increases with the increase of WHSV. The gas composition changes little with the change of WHSV $\left(0.77-1.08 \mathrm{~h}^{-1}\right)$, and the

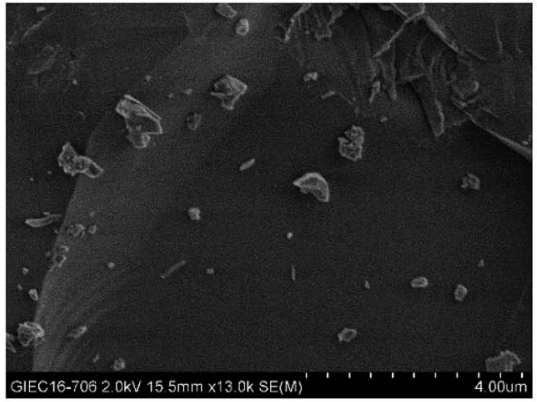

(a)

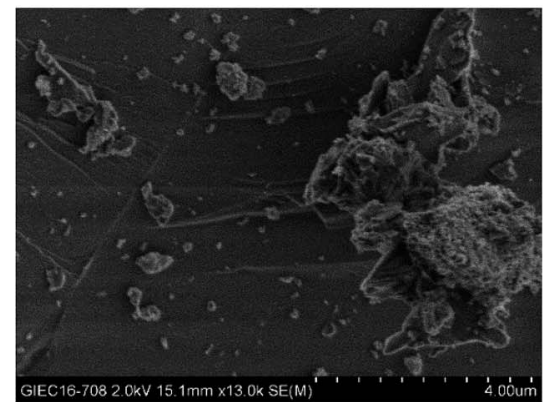

(b)

Fig. 13 SEM images of the TF-Ni/olivine catalysts: (a) fresh TF-Ni/olivine (b) spent TF-Ni/olivine. 


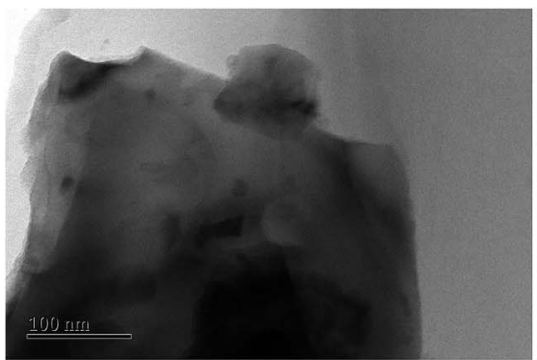

(a)

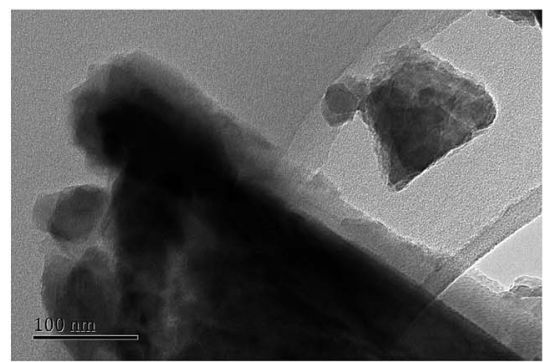

(b)

Fig. 14 TEM images of fresh and spent TF-Ni/olivine catalysts: (a) fresh TF-Ni/olivine (b) spent TF-Ni/olivine.

CO content decreases with the increase of deposited carbon. These results imply the higher the amount of the catalyst, the more active sites involved in the reaction, leading to a faster reaction rate and lower carbon deposition.

3.2.3 Effect of S/C. Experiments on the effect of the S/C ratio in toluene steam reforming were carried out using the TF-Ni/ olivine catalyst at $850{ }^{\circ} \mathrm{C}$ with a WHSV of $0.9 \mathrm{~h}^{-1}$, as shown in Fig. 11. Toluene conversion decreases slightly while carbon deposition decreases rapidly as the $\mathrm{S} / \mathrm{C}$ ratio changes from 0.29 to 0.88 . The most exciting implication is that the carbon deposition rate is very low (less than $1 \%$ ) when the $\mathrm{S} / \mathrm{C}$ ratio is more than 0.88. Similar results were obtained in the literature,,$^{22,25,46}$ which demonstrated the strong interaction between $\mathrm{NiO}-\mathrm{MgO}$ solid solution and Fe-Ni alloy with the olivine structure during thermal fusion, promoting the resistance of carbon deposition. With the increase of steam added ( $\mathrm{S} / \mathrm{C}$ less than 1), the ratio of $\mathrm{H}_{2} / \mathrm{CO}$ becomes closer to the stoichiometric ratio of eqn (8). When the $\mathrm{S} /$ $\mathrm{C}$ ratio is greater than 1 , the toluene conversion decreases which may attribute to excessive steam, causing the active sites to be oxidized and to lose their catalytic activity. Under these conditions, some toluene undergo only the cracking reaction, and more

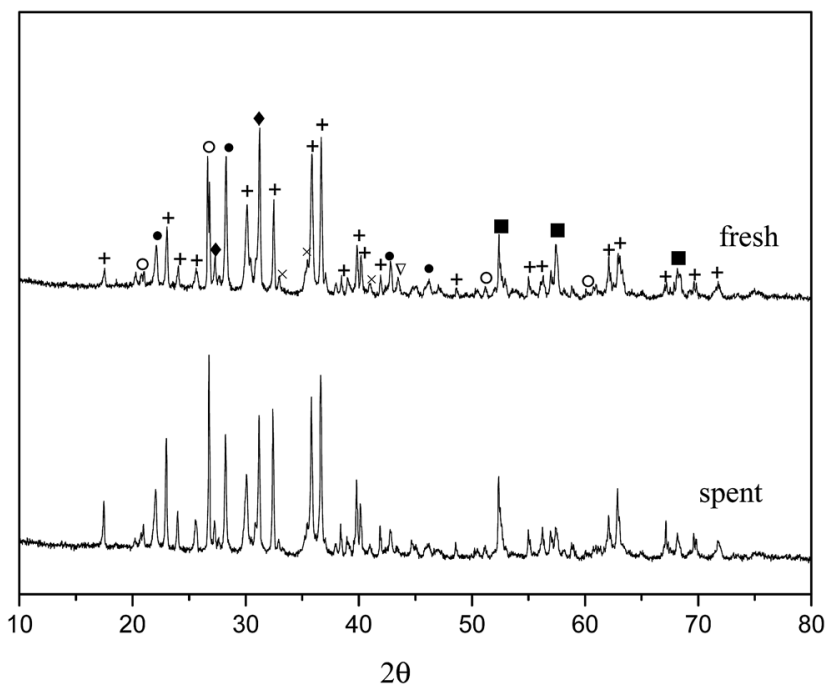

Fig. 15 XRD patterns of fresh and spent TF-Ni/olivine catalysts + $\mathrm{Mg}_{2} \mathrm{SiO}_{4} ; \mathrm{MgSiO}_{3} ; \mathrm{O}:(\mathrm{Fe}, \mathrm{Ni}) ; \times: \mathrm{Fe}_{2} \mathrm{O}_{3} ; \boldsymbol{O}:(\mathrm{Mg}, \mathrm{Fe}) \mathrm{SiO}_{3} ; \nabla: \mathrm{Ni} ;$ $(\mathrm{Ni}, \mathrm{Mg})_{2} \mathrm{SiO}_{4}$.
$\mathrm{H}_{2}$ and less $\mathrm{CO}$ are produced compared to catalytic reforming with steam. This is the reason that the $\mathrm{H}_{2} / \mathrm{CO}$ ratio increases when the $\mathrm{S} / \mathrm{C}$ ratio is greater than 1 . We can also note that the content of $\mathrm{CO}_{2}$ increases when the $\mathrm{S} / \mathrm{C}$ ratio is near 1 , which implies superfluous steam reacting with toluene to produce carbon dioxide (eqn (9)) instead of carbon monoxide (eqn (8)). This could also be due to the excess steam, causing eqn (11) to be expressed as follows.

$$
\mathrm{CO}+\mathrm{H}_{2} \mathrm{O} \Leftrightarrow \mathrm{CO}_{2}+\mathrm{H}_{2}, \Delta H_{900}{ }^{\circ} \mathrm{C}=-33 \mathrm{~kJ} \mathrm{~mol}^{-1}
$$

\subsection{Characterization of fresh and spent TF-Ni/olivine catalysts}

From the experiments on the optimization of the operating conditions above, we selected the TF-Ni/olivine catalyst, which showed a good catalytic performance when the reaction temperature was $850^{\circ} \mathrm{C}$, the WHSV was $0.9 \mathrm{~h}^{-1}$ and the $\mathrm{S} / \mathrm{C}$ ratio was 0.88 , to investigate the characterizations before and after the test.

The macroscopic morphology of the catalyst does not change much and remains granular after the reaction (Fig. 12). Fig. 13 presents the surface topography of fresh and spent TF-Ni/

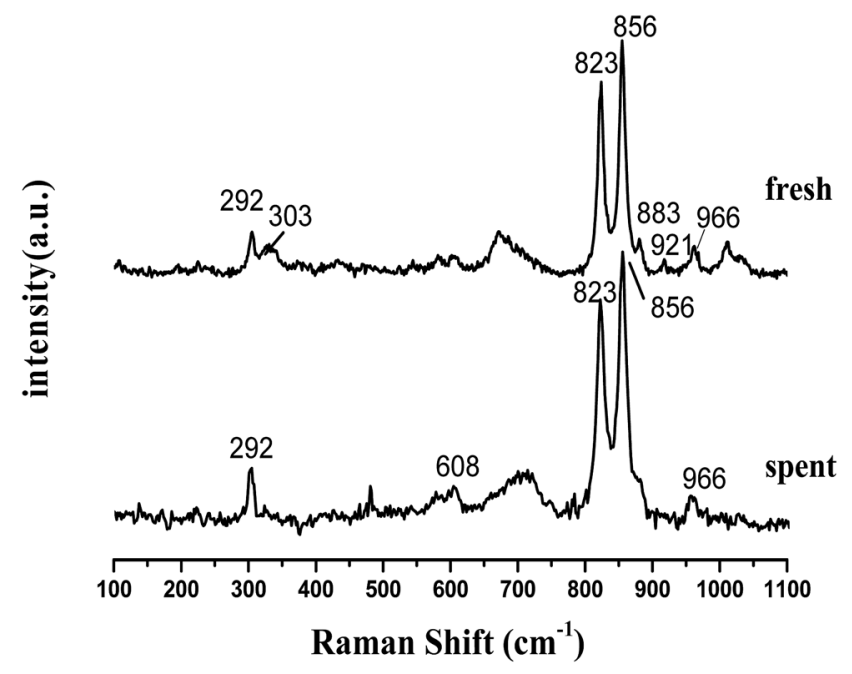

Fig. 16 Laser Raman spectra of fresh and spent TF-Ni/olivine catalysts. 

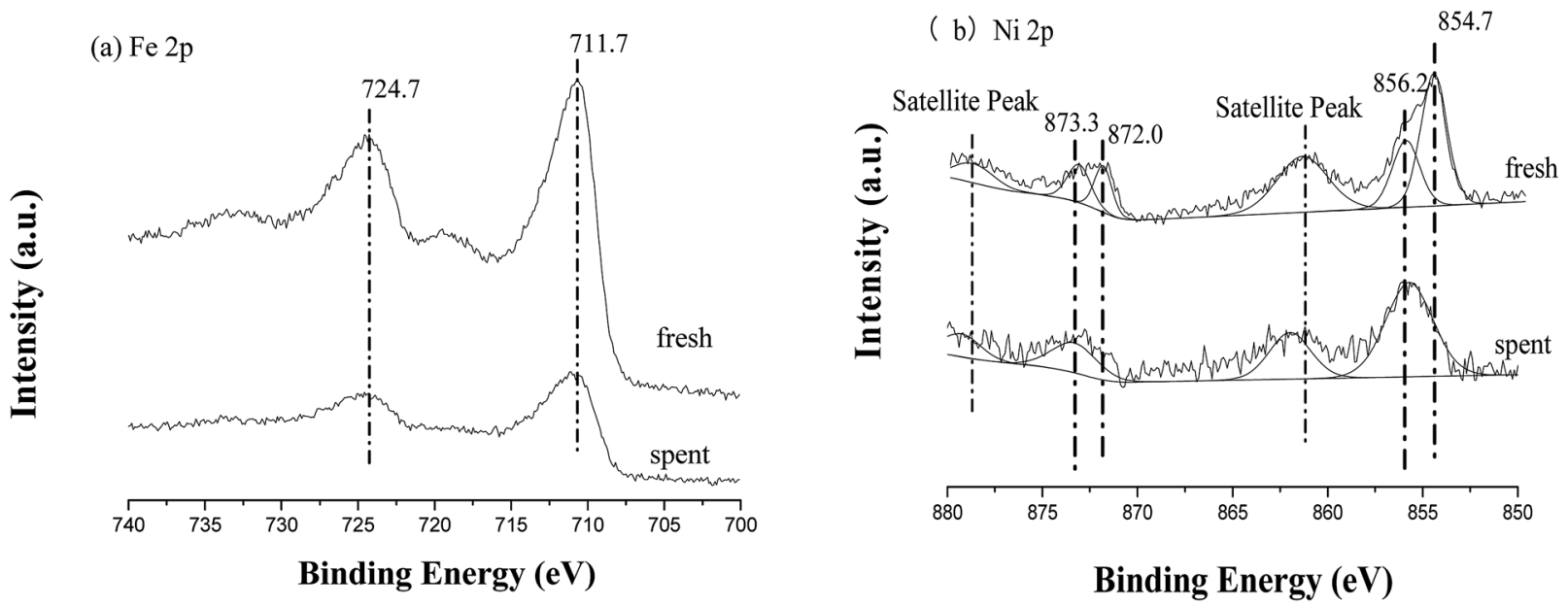

Fig. 17 X-ray photoelectron spectra of fresh and spent TF-Ni/olivine catalysts: (a) Fe 2p, (b) Ni 2p.

olivine catalyst; the results indicate that there is no obvious difference between them. The surface is still very compact and non-porous. Fig. 14 shows the TEM image of the fresh and spent TF-Ni/olivine, dark spots are metallic particles and the larger material is the olivine support, due to the complex composition of olivine support, the metallic particles do not appear as a regular spherical shape as in the literature,$^{45}$ but appear in irregular flakes. The average size of the metallic particles were estimated to be $30-50 \mathrm{~nm}$ (41.9 $\mathrm{nm}$ calculated by the Scherrer equation, the Bragg angle of $2 \theta$ using $26.7^{\circ}$ in the XRD) on the fresh TF-Ni/olivine catalyst. After the reaction, a slight agglomeration between the metallic particles is observed, the metallic particles size were about $60-80 \mathrm{~nm}(72.1 \mathrm{~nm}$ calculated by the Scherrer equation, the Bragg angle of $2 \theta$ using $26.7^{\circ}$ in the XRD). The XRD patterns of the two catalysts shown in Fig. 15 show that the main crystal structure has no change but the height of the $\mathrm{Mg}_{2} \mathrm{SiO}_{4}$ and $\mathrm{MgSiO}_{3}$ peaks slightly increase in the spent catalyst, which indicates an increase in the crystallite size. The lattice volume increases, which may suggest that Fe has displaced $\mathrm{Mg}$ in the TF-Ni/olivine structure. ${ }^{27}$ In addition, the major difference between fresh and spent TF-Ni/olivine from the Laser Raman spectra (Fig. 16) is the bands near $292 \mathrm{~cm}^{-1}$. This suggests that the oxidized Fe content has increased.

The XPS results of fresh and spent TF-Ni/olivine are shown in Fig. 17. Compared with that of the fresh catalyst, the surface compositions (mainly Fe 2p and Ni 2p) of the spent catalyst change little; similar spectra for all regions are summarized elsewhere. ${ }^{26}$ For Fe 2p, the binding energy near $711.7 \mathrm{eV}$ and $724.7 \mathrm{eV}$ is still in the form of an oxide. In contrast, Ni $2 \mathrm{p}$ exhibits some changes. Metallic Ni $\left(2 \mathrm{p}_{3 / 2}\right.$ near $854.7 \mathrm{eV}, 2 \mathrm{p}_{1 / 2}$ near $872.0 \mathrm{eV}$ ) disappears, and all $\mathrm{Ni}$ exists in the form of the oxidation state after burning the carbon on the TF-Ni/olivine surface.

\section{Conclusion}

The performances of olivine catalysts synthesized by thermal fusion in toluene steam reforming were sufficiently investigated. TF-Ni/olivine exhibited higher toluene conversion and lower carbon deposition rates compared with TF-olivine and raw olivine because with the addition of metallic $\mathrm{Ni}, \mathrm{Fe}-$ $\mathrm{Ni}$ alloy was formed on the catalyst surface. The thermal fusion method made the interaction between the olivine structure and active substance (Fe, $\mathrm{Ni}$, or alloy) stronger, which also promoted the catalytic performance of the catalyst.

For the TF-Ni/olivine catalyst, the toluene conversion increased with increased reaction temperature. A satisfactory catalytic ability of the TF-Ni/olivine catalyst was obtained when WHSV was $0.9 \mathrm{~h}^{-1}$. It was exciting to observe that the carbon deposition rate decreased (reached less than 1\%) with the increase of the $\mathrm{S} / \mathrm{C}$ ratio. However, the toluene conversion decreased slightly when the steam was too much, which may be due to the excess steam that oxidized the active states. Comparing the characteristics between fresh and spent TF-Ni/ olivine, the structure of TF-Ni/olivine still maintained its integrity. Thus, thermal fusion in olivine catalysts is an effective treatment method for the in situ removal of tar during biomass gasification.

\section{Acknowledgements}

The authors are grateful for financial support from the National Natural Science Foundation of China (No. 51506208). This work was also supported by the Guangdong Province "Pearl River Talent Program", the Third Batch; the Science and Technology Projects of Guangdong (2015A020215023) and State Key Laboratory Breeding Base of Coal Science and Technology Cofounded by Shanxi Province and the Ministry of Science and Technology, Taiyuan University of Technology (MKX201701).

\section{References}

1 A. A. Ahmad, N. A. Zawawi, F. H. Kasim, et al., Assessing the gasification performance of biomass: A review on biomass gasification process conditions, optimization and 
economic evaluation, Renewable Sustainable Energy Rev., 2016, 53, 1333-1347.

2 V. Claude, C. Courson, M. Köhler, et al., Overview and Essentials of Biomass Gasification Technologies and Their Catalytic Cleaning Methods, Energy Fuels, 2016, 30(11), 8791-8814.

3 S. Anis and Z. A. Zainal, Tar reduction in biomass producer gas via mechanical, catalytic and thermal methods: A review, Renewable Sustainable Energy Rev., 2011, 15(5), 2355-2377.

4 N. Abdoulmoumine, S. Adhikari, A. Kulkarni, et al., A review on biomass gasification syngas cleanup, Appl. Energy, 2015, 155, 294-307.

5 X. Nitsch, J. M. Commandré, P. Clavel, et al., Conversion of phenol-based tars over olivine and sand in a biomass gasification atmosphere, Energy Fuels, 2013, 27(9), 54595465.

6 D. Li, M. Tamura, Y. Nakagawa, et al., Metal catalysts for steam reforming of tar derived from the gasification of lignocellulosic biomass, Bioresour. Technol., 2015, 178, 5364.

7 Y. Shen, Chars as carbonaceous adsorbents/catalysts for tar elimination during biomass pyrolysis or gasification, Renewable Sustainable Energy Rev., 2015, 43, 281-295.

8 S. Karnjanakom, G. Guan, B. Asep, et al., Catalytic steam reforming of tar derived from steam gasification of sunflower stalk over ethylene glycol assisting prepared $\mathrm{Ni}$ / MCM-41, Energy Convers. Manage., 2015, 98, 359-368.

9 M. Artetxe, M. A. Nahil, M. Olazar, et al., Steam reforming of phenol as biomass tar model compound over $\mathrm{Ni} / \mathrm{Al}_{2} \mathrm{O}_{3}$ catalyst, Fuel, 2016, 184, 629-636.

10 G. Oh, S. Y. Park, J. G. Lee, et al., Steam Reforming of Tar Produced from Biomass Gasification Using Ni/Ru-X/Al $\mathrm{Al}_{2} \mathrm{O}_{3}$ (X = K or Mn) Catalyst, Clean Technol., 2016, 22(1), 53-61.

11 J. Tao, L. Zhao, C. Dong, et al., Catalytic steam reforming of toluene as a model compound of biomass gasification tar using Ni-CeO ${ }_{2} / \mathrm{SBA}-15$ catalysts, Energies, 2013, 6(7), 32843296.

12 C. Christodoulou, D. Grimekis, K. D. Panopoulos, et al., Comparing calcined and un-treated olivine as bed materials for tar reduction in fluidized bed gasification, Fuel Process. Technol., 2014, 124, 275-285.

13 R. Michel, A. Łamacz, A. Krzton, et al., Steam reforming of $\alpha$ methylnaphthalene as a model tar compound over olivine and olivine supported nickel, Fuel, 2013, 109, 653-660.

14 H. O. A. Fredriksson, R. J. Lancee, P. C. Thüne, et al., Olivine as tar removal catalyst in biomass gasification: Catalyst dynamics under model conditions, Appl. Catal., B, 2013, 130, 168-177.

15 F. Miccio, B. Piriou, G. Ruoppolo, et al., Biomass gasification in a catalytic fluidized reactor with beds of different materials, Chem. Eng. J., 2009, 154(1), 369-374.

16 F. García-Labiano, P. Gayán, L. F. de Diego, et al., Tar abatement in a fixed bed catalytic filter candle during biomass gasification in a dual fluidized bed, Appl. Catal., B, 2016, 188, 198-206.
17 T. Berdugo Vilches, J. Marinkovic, M. Seemann, et al., Comparing Active Bed Materials in a Dual Fluidized Bed Biomass Gasifier: Olivine, Bauxite, Quartz-Sand, and Ilmenite, Energy Fuels, 2016, 30(6), 4848-4857.

18 M. Kuba, H. He, F. Kirnbauer, et al., Mechanism of Layer Formation on Olivine Bed Particles in Industrial-Scale Dual Fluid Bed Gasification of Wood, Energy Fuels, 2016, 30(9), 7410-7418.

19 R. Zhang, Y. Wang and R. C. Brown, Steam reforming of tar compounds over Ni/olivine catalysts doped with $\mathrm{CeO}_{2}$, Energy Convers. Manage., 2007, 48(1), 68-77.

$20 \mathrm{R}$. Zhang, H. Wang and X. Hou, Catalytic reforming of toluene as tar model compound: Effect of Ce and Ce-Mg promoter using Ni/olivine catalyst, Chemosphere, 2014, 97, 40-46.

21 X. Yang, S. Xu, Z. Chen, et al., Improved nickel-olivine catalysts with high coking resistance and regeneration ability for the steam reforming of benzene, React. Kinet., Mech. Catal., 2013, 108(2), 459-472.

22 D. Swierczynski, C. Courson, L. Bedel, et al., Characterization of $\mathrm{Ni}-\mathrm{Fe} / \mathrm{MgO} /$ olivine catalyst for fluidized bed steam gasification of biomass, Chem. Mater., 2006, 18(17), 4025-4032.

23 D. Swierczynski, C. Courson and A. Kiennemann, Study of steam reforming of toluene used as model compound of tar produced by biomass gasification, Chem. Eng. Process., 2008, 47(3), 508-513.

24 J. N. Kuhn, Z. Zhao, A. Senefeld-Naber, et al., Ni-olivine catalysts prepared by thermal impregnation: Structure, steam reforming activity, and stability, Appl. Catal., A, 2008, 341(1), 43-49.

25 Z. Zhao, J. N. Kuhn, L. G. Felix, et al., Thermally impregnated Ni-olivine catalysts for tar removal by steam reforming in biomass gasifiers, Ind. Eng. Chem. Res., 2008, 47(3), 717-723.

26 J. N. Kuhn, Z. Zhao, L. G. Felix, et al., Olivine catalysts for methane-and tar-steam reforming, Appl. Catal., B, 2008, 81(1), 14-26.

27 Z. Zhao, N. Lakshminarayanan, J. N. Kuhn, et al., Optimization of thermally impregnated $\mathrm{Ni}$-olivine catalysts for tar removal, Appl. Catal., A, 2009, 363(1), 64-72.

28 M. Virginie, C. Courson and A. Kiennemann, Toluene steam reforming as tar model molecule produced during biomass gasification with an iron/olivine catalyst, C. R. Chim., 2010, 13(10), 1319-1325.

29 B. A. Kolesov and C. A. A. Geiger, Raman spectroscopic study of Fe-Mg olivines, Phys. Chem. Miner., 2004, 31(3), 142-154.

30 K. E. Kuebler, B. L. Jolliff, A. Wang, et al., Extracting olivine (Fo-Fa) compositions from Raman spectral peak positions, Geochim. Cosmochim. Acta, 2006, 70(24), 6201-6222.

31 C. C. Lin, Vibrational Spectroscopic Study of the System $\alpha$ $\mathrm{Co}_{2} \mathrm{SiO}_{4}-\alpha-\mathrm{Ni}_{2} \mathrm{SiO}_{4}$, J. Solid State Chem., 2001, 157(1), 102109.

32 J. R. Petriglieri, E. Salvioli-Mariani, L. Mantovani, et al., Micro-Raman mapping of the polymorphs of serpentine, $J$. Raman Spectrosc., 2015, 46(10), 953-958. 
33 A. L. Auzende, I. Daniel, B. Reynard, et al., High-pressure behaviour of serpentine minerals: a Raman spectroscopic study, Phys. Chem. Miner., 2004, 31(5), 269-277.

34 I. Chamritski and G. Burns, Infrared-and Raman-active phonons of magnetite, maghemite, and hematite: a computer simulation and spectroscopic study, J. Phys. Chem. B, 2005, 109(11), 4965-4968.

35 M. A. Legodi and D. De Waal, The preparation of magnetite, goethite, hematite and maghemite of pigment quality from mill scale iron waste, Dyes Pigm., 2007, 74(1), 161-168.

36 E. Talik, W. Zarek, M. Kruczek, et al., Characterization of olivine single crystals grown by the micro-pulling-down method and terrestrial olivine by XPS, Mössbauer, magnetic and EPR methods, Cryst. Res. Technol., 2006, 41(10), 979-987.

37 A. P. Grosvenor, M. C. Biesinger, R. S. C. Smart, et al., New interpretations of XPS spectra of nickel metal and oxides, Surf. Sci., 2006, 600(9), 1771-1779.

38 H. W. Nesbitt, D. Legrand and G. M. Bancroft, Interpretation of $\mathrm{Ni}_{2}$ p XPS spectra of Ni conductors and Ni insulators, Phys. Chem. Miner., 2000, 27(5), 357-366.

39 M. Koike, D. Li, H. Watanabe, et al., Comparative study on steam reforming of model aromatic compounds of biomass tar over $\mathrm{Ni}$ and $\mathrm{Ni}-\mathrm{Fe}$ alloy nanoparticles, Appl. Catal., A, 2015, 506, 151-162.

40 L. Wang, D. Li, M. Koike, et al., Catalytic performance and characterization of Ni-Fe catalysts for the steam reforming of tar from biomass pyrolysis to synthesis gas, Appl. Catal., A, 2011, 392(1), 248-255.

41 M. Koike, D. Li, Y. Nakagawa, et al., A Highly Active and Coke-Resistant Steam Reforming Catalyst Comprising Uniform Nickel-Iron Alloy Nanoparticles, ChemSusChem, 2012, 5(12), 2312-2314.

42 D. Li, M. Koike, L. Wang, et al., Regenerability of Hydrotalcite-Derived Nickel-Iron Alloy Nanoparticles for Syngas Production from Biomass Tar, ChemSusChem, 2014, 7(2), 510-522.

43 D. Świerczyński, S. Libs, C. Courson, et al., Steam reforming of tar from a biomass gasification process over Ni/olivine catalyst using toluene as a model compound, Appl. Catal., $B, 2007,74(3), 211-222$.

44 K. Nakamura, T. Miyazawa, T. Sakurai, et al., Promoting effect of $\mathrm{MgO}$ addition to $\mathrm{Pt} / \mathrm{Ni} / \mathrm{CeO}_{2} / \mathrm{Al}_{2} \mathrm{O}_{3}$ in the steam gasification of biomass, Appl. Catal., B, 2009, 86(1), 36-44.

45 D. Li, L. Wang, M. Koike, et al., Steam reforming of tar from pyrolysis of biomass over $\mathrm{Ni} / \mathrm{Mg} / \mathrm{Al}$ catalysts prepared from hydrotalcite-like precursors, Appl. Catal., B, 2011, 102(3), 528-538.

46 Z. Zhao, N. Lakshminarayanan, S. L. Swartz, et al., Characterization of olivine-supported nickel silicate as potential catalysts for tar removal from biomass gasification, Appl. Catal., A, 2015, 489, 42-50. 